\title{
Shocking Behavior: Random Wealth in Antebellum Georgia and Human Capital Across Generations
}

\author{
Hoyt Bleakley ${ }^{\dagger}$ and Joseph Ferrie ${ }^{\dagger \dagger}$ \\ tUniversity of Michigan \& NBER \\ ${ }^{\dagger+}$ Northwestern University \& NBER
}

\begin{abstract}
Does the lack of wealth constrain parents' investments in the human capital of their descendants? We conduct a nearly fifty-year followup of an episode in which such constraints would have been plausibly relaxed by a random allocation of substantial wealth to families. We track descendants of participants in Georgia's Cherokee Land Lottery of 1832, in which nearly every adult white male in Georgia took part. Winners received close to the median level of wealth - a large financial windfall orthogonal to participants' underlying characteristics that might have also affected their children's human capital. Although winners had slightly more children than non-winners, they did not send them to school more. Sons of winners have no better adult outcomes (wealth, income, literacy) than the sons of non-winners, and winners' grandchildren do not have higher literacy or school attendance than non-winners' grandchildren. This suggests only a limited role for family financial resources in the formation of human capital in the next generations in this environment and a potentially more important role for other factors that persist through family lines.
\end{abstract}

\section{Introduction}

Investment by parents in the human capital of their children can be constrained when capital markets are imperfect and borrowing against future labor earnings is precluded. In such situations, much of the productive potential of the children may go unrealized, leaving both them and society as a whole poorer as a result. Nevertheless, the importance of such constraints is difficult to assess in the absence of randomized perturbations to family wealth, as parental wealth might predict child outcomes for reasons other than borrowing constraints, such as parents' possession of underlying characteristics (e.g. ability, ambition, or access to better investment opportunities) that helped them accumulate more assets in the first place. If these characteristics are passed on to their children, those children would exhibit better outcomes regardless of their parents' direct investments in them.

We examine the effects of a substantial, random wealth disbursement to parents - winning one of more than 18,000 parcels of land in a large-scale lottery in the U.S. state of Georgia (the 1832 Cherokee Land Lottery) on children and grandchildren — on their children and grandchildren over nearly fifty after the windfall. ${ }^{1}$ This allows us to separate the impact of parental resource constraints from other influences on their children's outcomes. 
At this time in Georgia, as in most modern settings, parents' resources and outcomes are linked to the outcomes of their descendants; correlations were both substantively large and statistically significant between parental resources and the school attendance, literacy, wealth, and occupations of their children and and even their grandchildren. ${ }^{2}$ We use the lottery's rules to identify in 185014,000 adult white males who had been eligible to participate in the 1832 lottery. From these eligibles, we identify winners - our treated group - using a list published by the state of Georgia (Smith 1838), while lottery-eligible men not found in the list serve as a control group. The lottery's losers and winners look quite similar in a series of balancing tests using outcomes determined prior to the lottery. ${ }^{3}$ The netpresent-value of land won was at least $\$ 464$ and perhaps as high as $\$ 716$ in 1850 dollars, and winners were, on average, $\$ 748$ richer in 1850 than the controls, almost two decades after the lottery. ${ }^{4}$

Becker and Tomes (1986) modeled the decision made by parents to invest in their children, subject to a budget constraint and the presence of "a family's cultural and genetic 'infrastructure."' (1986, p. S6). In this setting, wealthier and better-educated parents face a different budget constraint than poorer parents, resulting in a correlation in outcomes across generations even if all families possess the same "infrastructure." Conversely, parents facing identical budget constraints might also see different outcomes for their children if their "infrastructures" are different. Some of the advantages enjoyed by certain parents might be dissipated (i.e., not exclusively generate better per-child outcomes) to the extent that they result in greater fertility. Nevertheless, Becker and Tomes (1986) predict on the basis of studies available in 1986 that any earnings advantage would be erased within three generations.

A large number of studies have examined contemporary correlations in human capital across generations (Chevalier 2004; Black et al. 2005; Oreopoulos et al. 2006). These exercises are

\footnotetext{
${ }^{1}$ See Figure 1 for the location of Old Cherokee County, the area settled through this lottery, as well as the counties in the Southeast to which the population we examine had moved by 1850 . Wishart (1995) shows that corn production by the Cherokee in this area compared favorably to that of white farmers in Dekalb County, Georgia, and in the valley and mountain regions of Virginia. Gregg and Wishart (2012) calculate the full costs of the removal of the Cherokee.

${ }^{2}$ See online Appendix Figure 1 for just one example: the strong, positive relationship between a father's position in the wealth distribution and the probability that his children attended school. The existence of intergenerational correlations in outcomes in the nineteenth century U.S. is clear: for example, Long and Ferrie (2013) show the links between the occupations of fathers and sons in the U.S., 1850-80. Sacerdote (2005) examines father-son links after the Civil War and finds that it took roughly two generations for the descendants of those born into slavery in the U.S. (and faced severely limited opportunities for human or financial capital accumulation) to converge to the human capital outcomes of blacks who were born free. In Britain, Clark and Cummins (2013) use evidence from rare surnames to show how advantages in educational opportunities (attendance at Oxford and Cambridge) persist for eight centuries. Clark (2014) shows persistent correlation of outcomes within family lines in a variety of settings, over many generations. Olivetti and Passerman (forthcoming, 2015) show high nineteenth century intergenerational income correlations for the nineteenth century U.S., and Lindahl et al. (2015) show the persistence of outcomes within family lines for up to four generations in Sweden.

${ }^{3}$ We performed sensitivity analyses, in addition to these balancing tests. First, using a placebo sample constructed by assuming the lottery required residence in South Carolina for three years before 1832, we find no pseudo-treatment, in contrast to what we find for Georgia (online Appendix B). Second, analysis of a sample linking the full 1830 and 1850 Georgia census indices — a lessconstrained population than our sample of eligibles-yields the same results on outcomes for children as our original sample (online Appendix C). Finally, we control for characteristics of the person's name throughout the analysis, as both the identification of winners in our eligible population and the observation of children's and grandchildren's outcomes in post-1850 censuses relied on matching individuals by name, and find that all results are robust to inclusion of these controls.

${ }^{4}$ See Bleakley and Ferrie (2013) for these calculations. Though our wealth measure is self-reported in the census of population, there is a strong correspondence between this measure and an independent measure- the value of wealth as reported by the local tax assessor. We show this correspondence in online Appendix F. An unskilled laborer in the South Atlantic region earned \$0.74 per day in 1849 (Margo and Villaflor 1987, p. 880), so \$748 in 1850 represented 1,010 days of work by an unskilled worker. Assuming 200 work days/year for such workers, lottery winnings of $\$ 748$ represented 5.1 years of unskilled labor.
} 
centered on plausibly exogenous variation in educational attainment that is not the product of variation in ability or other unobserved family characteristics. Studies that examine instead the relaxation of the family's budget constraint are less common, but examples include Mayer (1997), Baird, McIntosh, and Özler (2011), Dahl and Lochner (2012), Bursztyn and Coffman (2012), and Akresh et al. (2013). In the present study, we focus on a random shock to financial resources to separate these effects.

The 1832 land lottery has several advantages when it comes to studying this question. First, the lottery generated a shock to an individual's wealth that we can plausibly expect was exogenous to his characteristics. Second, registration in this lottery was cheap and widespread (nearly all white males age 18+ in the state in 1832 were registered, by our calculations), unlike many studies of lotteries whose participants are a small and selective subset of the population. Third, the prize in this lottery was a claim on a parcel of land with an average value close to the median wealth of the period. Fourth, lottery winnings were essentially a pure wealth shock - there was no homesteading requirement and the claim could be readily liquidated without even setting foot on the land. Finally, we are able to undertake a long-run followup on the effects of this wealth shock and examine family outcomes up to five decades after the lottery.

In the case studied here, the shock came well after parents had completed their own schooling, leaving little scope to alter their own human capital. But relaxing their budget constraint would have allowed them to invest more in the human capital of their children, if indeed such investment would have otherwise been constrained by lack of parental wealth. If instead human capital were unaffected in the next generations, this suggests that the intergenerational correlation in outcomes is driven not by wealth constraints but by more fundamental, perhaps family-specific effects (such as the "family's cultural and genetic "infrastructure" "in the Becker and Tomes 1986 model).

We find that lottery winners had only slightly higher (post-lottery) fertility than losers, but were no more likely to send their children to school. ${ }^{5}$ As we follow these children into adulthood in 1860,1870 , and 1880 , we find that sons' 1860 and 1870 wealth is not statistically distinguishable between control and treatment groups. ${ }^{6}$ Further, in 1880 , we do not find differences in occupational standing or literacy as a function of their father's lottery status. In 1880, the grandchildren themselves do not have significantly greater literacy or school attendance if their grandfather was a lottery winner. Treated families have fewer grandchildren per son in 1880, which roughly offsets the small fertility effect in the previous generation, leaving a statistically similar number of grandchildren by lottery status.

The absence of a lottery effect on descendants' human capital contrasts with cross-sectional evidence of returns to skill in nineteenth-century Georgia (Bleakley and Ferrie 2014) and of intergenerational correlations in other outcomes, as well as with narrative evidence of an

\footnotetext{
${ }^{5}$ Contextual influences on fertility and school attendance are not apparently an important mechanism for these results: effects are not sensitive to controlling for county of residence, nor do we find evidence that lottery winners move to counties with unusual fertility, schooling, land value, slave intensity, farm sizes, land improvement, urbanization, or transport access.

$6^{6}$ evertheless, a mechanical split of the 'extra' 1832 paternal wealth among his children would suggest a treatment effect in 1870 of $\$ 140$ (in 1850 dollars), which we can reject for reasonable discount rates.
} 
awareness among Georgia's poorer farmers of the value of investment in education. ${ }^{7}$ This indicates that winners did not use their windfall to relax a financial resource constraint on human capital investment in their children. This is instead consistent with intergenerational correlations reflecting the presence of deeper, underlying characteristics that persist through family lines and are associated with superior outcomes.

\section{The Cherokee Land Lottery in Northwest Georgia, 1832}

Georgia placed most of its land in the hands of the public through a series of land lotteries. ${ }^{8}$ As new land was acquired by the state in treaties with the indigenous population, lotteries were conducted, the last in 1832 following the eviction of the Cherokee from northwest Georgia. The rules were simple: every male age 18 and older who had resided in Georgia for the three years prior to the 1832 drawing was entitled to one draw, and any male who had a wife or had children under 18 and met the three-year residency requirement was entitled to an additional draw. ${ }^{9}$ A slip of paper was made out with a name on it for each draw, and these roughly 85,000 slips were placed in a large drum. The location of each 160 acre parcel of land was written on a slip of paper, and these 18,309 slips were placed in a second drum, together with over 66,000 blank slips, making the numbers in the two drums identical. Slips were then drawn one at a time from each drum after the drums had been mixed, and were paired up. Names matched to a parcel location were winners; names matched to a blank slip were losers. The lottery was thus doubly random: winning was random, as was the quality of the parcel received, conditional on winning. In online Appendix A, we calculate that $98 \%$ of eligible males age 18 and over registered.

Once the lottery was completed, winners could immediately sell their winning draw. Unlike land distributions in many Midwestern states, there was no requirement that the recipient spend any time on the land or make any improvements whatsoever. The only requirement imposed was that winners register their claim and pay an $\$ 18$ registration fee to the state. ${ }^{10}$ The land could not be immediately occupied, however, as the Cherokee Nation was engaged in legal action to fight their eviction, and the final ruling in favor of the state did not come until $1838 .{ }^{11}$ As a result, some lottery winners may have exercised their option of immediately "flipping" their property.

\footnotetext{
${ }^{7}$ Bleakley and Ferrie (2014) show that literacy and childhood school attendance — themselves strongly predicted by parents' wealth - predict adult wealth, and sons with more siblings tend to have worse adult outcomes. Whether this reflects a causal effect is uncertain, but the standard methodologies for measuring these relationships indicate their presence in one form or another in midnineteenth century Georgia. In a simulation exercise in online Appendix D, we show that the observed effect on sons' outcomes are smaller than those we would predict based on the relationships between parents' wealth and sons' outcomes we observe in our control sample. That random wealth shocks generate negligible changes to sons' outcomes despite positive correlations between sons' outcomes and parents' wealth in the population suggests that the latter are not causal and may suffer from the omission of some important variable associated with better outcomes for both some parents and for their children.

${ }^{8}$ This summary of the rules is drawn from State of Georgia (1831, pp. 131-139).

${ }^{9}$ Widows, orphans, soldiers, and the disabled were also entitled to draws, and both prisoners and some outlaws were excluded, but we will focus our attention on adult males with children (all of whom will have been eligible for two draws) because for this group it is possible to identify in the 1850 census individuals who had been eligible in 1832 based on the ages and birthplaces of their children reported in 1850. The residency rule for males was 4 years in the original 1830 law, but was amended to three years in 1831; see State of Georgia (1832, p. 142).

${ }^{10}$ The registration fee need not have been an obstacle to liquidity-constrained winners in that there were many who simply sold the claim itself.

${ }^{11}$ Despite the on-going litigation (the outcome of which was never in doubt, as the Indian Removal Act had already been upheld by the courts and used successfully in numerous prior instances), some settlers still relocated to the area before 1838, and some transactions for land awarded in the 1832 land lottery took place in the years from 1832 to 1838 . Weiman (1991) shows that the
} 
We estimate that the value of a winning draw was between $\$ 464$ and $\$ 716$ in 1850 for a 160 acre parcel. In Bleakley and Ferrie (2013, Table 2), we find that winners were in fact between $\$ 572$ and $\$ 923$ wealthier (depending on the specification we use) than losers by 1850. The midpoint of this range (\$748) is the equivalent of 1,010 days of earnings for an unskilled laborer in the South at this time, or just over 5 years at 200 work days per year. ${ }^{12}$ Even if they sold their parcel between 1832 and 1850 and bought land that rose in value at a similar rate, we would also expect them to be considerably wealthier in 1850 than lottery losers. Those who sold out before the uncertainty over the timing of the expulsion of the Cherokee might have received somewhat less than this, but the timing was the only source of uncertainty in this process, as the Indian Removal Act of 1830 under which the eviction was conducted had already been applied elsewhere. ${ }^{13}$

\section{Data}

\subsection{Data Sources and Construction}

The present study follows up on the outcomes of lottery winners and losers and their children and grandchildren. In order to do this, we first need to identify who was eligible, and who among them won. We find these individuals, their children, and their childrens' children in later, publicly available data sources, and ascertain their outcomes. We initially search for these individuals in the Census manuscripts of 1850-1880 using a preliminary version of the full-count file for the 1850 census from the IPUMS project, the full-count file for the 1880 census from the NAPP project, and also indices to the 1860 and 1870 censuses searchable on Ancestry.com.

The names of winners in the 1832 Georgia land lottery were published in Smith (1838), who lists each parcel in the 1832 lottery area and the name of the winner of that parcel, as well as the county and minor civil division where the winner resided in 1832 . There is no surviving state-wide list of all participants from which we could construct a control population to compare to those treated by winning the lottery. To create the control population, we exploited the lottery's eligibility requirements and information available in the 1850 Census of Population, which identifies all household members by name, age, and state of birth. The bulk of those eligible to participate in the lottery had to have been males age 18+ in 1832 who had been present in Georgia continuously over the preceding three years. Using the fullcount file created by the transcription of the 1850 census, we identified all white males who (1) would have been age $18+$ in 1832, (2) were present anywhere in the U.S. in 1850, (3) had at least one child who was born in Georgia 1829-1832, and (4) had no children born outside Georgia in the same interval. There were 14,306 individuals who met these criteria

\footnotetext{
market for the 1821 and 1827 land lottery claims was already active before 1830. Old Cherokee County was divided into Forsyth, Lumpkin, Union, Cobb, Gilmer, Murray, Cass (now Bartow), Floyd, and Paulding Counties by the state legislature on December 3, 1832. Though these counties could not be legally occupied until 1838 by winners in the 1832 lottery, the deed records from these places nonetheless report numerous transactions for plots within their borders in the years 1833-37. In just new Cherokee County hundreds of pre-1838 sales occurred (see http://deedsrecords.cherokeega.com/). Shadburn (1990) reports that there were already 11,500 white settlers in Old Cherokee County by 1834.

12 An unskilled laborer in the South Atlantic region earned \$0.74 per day in 1849 (Margo and Villaflor 1987, p. 880), so \$748 in 1850 represented 1,010 days of work by an unskilled worker. Assuming 200 work days/year for such workers, lottery winnings of $\$ 748$ represented 5.1 years of unskilled labor.

${ }^{13}$ The bottom third of Cherokee County was thought to contain gold, and was distributed in a separate lottery in smaller, 40-acre parcels. We focus only on the main lottery of 160 acre parcels.
} 
(see Figure 1 and Appendix Figure 3 for their 1850 locations), of whom 1,758 were subsequently linked - using their surname and given name - to exactly one individual in the Smith (1838) list of lottery winners. ${ }^{14}$ An additional 1,177 were linked to more than one individual in the Smith list. Thus the population "at risk" to have won land in the lottery was created using the eligibility criteria, and that uniformly-created population was then divided into "treated" (winners) and "control" (losers) groups based on whether they also appeared in Smith's list of winners. ${ }^{15}$

We were able to create an entirely separate sample of individuals eligible for the lottery and surviving to 1850 by taking all males in Georgia in the 1830 U.S. Census and locating them in the 1850 U.S. Census. This allowed us to compare our eligibles with a sample of eligibles who were not chosen on the basis of their 1850 household composition. These comparisons, shown in online Appendix C, reveal that our eligibles are men with somewhat more children, a somewhat compressed age distribution, and wealth portfolios tilted towards land and away from slaves, compared to the universe of all men linked $1830-50 .{ }^{16}$

For both the control and treated populations, information reported on the population schedule of the 1850 census and present in the $100 \%$ file (county of residence, and the names, number, and ages of all children) was combined with information we transcribed from the slave schedule of the 1850 census (the number and age and gender of slaves owned) that was created by census marshals concurrently with the population schedule. The value of slave wealth was estimated using slaves' age and gender and contemporaneous slave prices disaggregated by these characteristics. (Kotlikoff 1979). We then transcribed occupation, literacy, school attendance, and real estate value from the 1850 population schedule.

Linkage to later censuses was then performed to generate multigenerational outcomes for the control and treated populations. The male sons of the 1850 male household heads previously identified as the control and treatment groups were sought in the 1880 U.S. Census of Population in two ways: (1) the characteristics of 1850 sons (name, year of birth, birthplace, and parents' birthplaces) were used to locate them in the 1880 U.S. Census $100 \%$ File; ${ }^{17}$ and (2) individuals not successfully linked $1850-80$ were located in the Ancestry.com on-line 1850 U.S. Census index, where any hints to their 1880 record were

\footnotetext{
${ }^{14}$ An individual was considered to have been uniquely linked if exactly one individual in the Smith list appeared in the 1850 census group of eligibles with the correct given name and a surname that differed by no more than 15 units in the SPEDIS "phonetic distance" function in SAS (which assigns points to different sorts of transcription errors such as omitting a letter, sums the points, and adjusts for the name length). If several individuals were matched by given name and all had exactly the same SPEDIS value (below 15 ), the individual was considered to have been multiply matched.

15 Because the sample of the population "at risk" to have participated in the lottery relies on a measure of household composition (children of specific ages born in or out of Georgia) in 1850, we were concerned that this procedure could produce a sample with more children observed post-lottery (one of the outcomes we examine) if infant and child mortality was lower among lottery winners. We linked 4,978 households from 1840 to 1850 and again used linkage to the Smith list to divide them into winners and losers. We then compared the number of children age 0-4 in 1840 to the number of children 10-14 in 1850. This change (which should reflect mortality, as these children were still too young in 1850 to have left the households where they were initially observed in 1840) does not differ in either a statistically or economically significant way between winners and losers.

${ }^{16}$ This was possible because after our original submission, Ancestry.com made the index to the entire 1830 U.S. Census publicly available.

${ }^{17}$ When multiple matches were found in 1880 for the same 1850 individual, the match that minimized the SPEDIS "phonetic distance" between the 1850 individual sought and the 1880 individual located was chosen; if multiple 1880 individuals minimized this distance, the observations were rejected.
} 
followed. These hints are generated by Ancestry.com on the basis of both actual links among individuals made by genealogists in the construction of their family trees, and links generated by Ancestry.com through a machine learning process in which actual genealogistgenerated links were used as training data and the system then generated links automatically for individuals not previously linked by genealogists. When 1850 sons were identified as 1880 household heads through either of these mechanisms, the 1880 information on their entire 1880 family was transcribed (occupation was extracted from the $100 \%$ file, and we transcribed literacy and school attendance).

The male sons of the 1850 male household heads we previously identified as the control and treatment groups were sought in the 1870 U.S. Census of Population in three ways: (1) individuals linked to the $1880100 \%$ file in the manner described above were located in the Ancestry.com on-line 1880 U.S. Census index, from which any hints to their 1870 record were followed; (2) individuals not successfully linked 1850-80 in the manner described above had their hinted links forward from their 1850 census record on Ancestry.com followed; and (3) those who could not be traced through hints were sought directly in the 1870 index. When 1850 sons were identified as 1870 household heads through either of these mechanisms, their 1870 real estate and personal estate were transcribed.

The initial sample drawn from the 1850 census yielded 47,749 children age 5-17 whose school enrollment was observed (as the lottery occurred in 1832, the number of children under 18 years of age was also an outcome that we observed for families of winners and losers). The linkage to 1880 yielded 14,963 male children of lottery winners and losers whose outcomes could be observed in both 1850 and 1880 (46 percent of the 32,738 males under age 19 from 1850 sought), together with 40,658 grandchildren in 1880 of the original lottery winners and losers. The linkage to 1870 yielded 12,235 were adults in 1870 (37 percent of those sought), so their 1870 real and personal wealth was observed. ${ }^{18}$ These rates of linkage compare very favorably with other studies that have used linkage across U.S. census manuscripts in the second half of the twentieth century.

\subsection{Summary Statistics and Balancing Tests}

Table 1 presents the sample's summary statistics. Each variable appears in its own row, and each panel contains related variables. ${ }^{19}$ Column 1 displays values (means and, in parentheses, standard deviations) for the entire sample, while Columns 2 and 3 report, respectively, the corresponding values for lottery losers and winners. Column 4 reports $p$ values for a test of the null hypothesis that the means in Columns 2 and 3 are identical. The test is a simple bivariate regression on a dummy for lottery winner. Clustered standard errors are calculated throughout the analysis when the data have a grouped structure. Sample sizes are reported in square brackets.

We use two measures of winning land in the 1832 Cherokee Land Lottery (Panel A, Table 1). If an individual was uniquely matched to the list of winners (Smith, 1838), the first measure is coded to one; otherwise this measure is coded to zero. By this measure, $12.4 \%$ of

${ }^{18}$ Linkage to 1860 yielded 3,306 sons who were household heads.

${ }^{19}$ Portions of Tables 1 and 2 also appear in Bleakley and Ferrie (2013). 
our observations are lottery winners. This measure has a mean of zero for losers (Column 2) and a mean of one for winners (Column 3 ) by construction. The second measure is designed to account for the few cases where more than one individual is matched to the list of winners. If $n$ individuals are matched to the same winner, the match variable is recorded to $1 / n$. Our maintained assumption in constructing this measure is that one of the "tied" individuals in fact won a parcel, but in the absence of additional information, we can do no better than assigning equal probabilities of this even to all $n$ individuals in the "tied" set. The mean value for this measure of the probability of winning is $15.5 \%$, which is 3 percentage points higher than the original measure but similar to the winning rates in Columbia and Oglethorpe counties where we have actual lists of both lottery participants and lottery winners.

The second measure is higher than the first, as some individuals who were multiply matched have a zero for the first measure but $1 / n$ for the second. In 9 cases, there was one unique match to 1850 but several similar quality matches (e.g. the additional multiple matches had full given names but lacked middle initials, while the unique match had a middle initial and full given name in the winners list and in the 1850 census). In these cases, there is one observation with the value one and $n-1$ with the value zero by the first measure, and $n$ observations with the value $1 / n$ by the second. Overall, these two lottery winning indicators have a very high correlation.

Panel B of Table 1 presents outcomes determined before the 1832 lottery, which should not be affected by whether the individual was a lottery winner or loser. The comparisons between Columns 2 and 3 here represent a balancing test - an analysis of how well the treated group compares to the control group prior to the application of the treatment. Only one of the 13 outcomes in this panel is significantly different at the $10 \%$ level. Average age, the fraction born in Georgia, the number of coresident children present in 1850 and born in the three-year pre-lottery window, and the fraction of adults who could not read or write are similar in the control and treatment groups.

We then examine characteristics associated with the surname of each individual. Since surname was determined at birth and could not have been affected by the lottery, we would also expect no differences between the control and treatment groups in these measures. We account for minor variation in spelling by using the Soundex code for each. Surnames (prior to Soundex coding) are 6.2 characters in length on average, though this measure is slightly lower for lottery winners. On average, each individual's surname occurs 36 times in the sample, with no difference between winners and losers. Surnames began with the letter "M" or "O" (a rough indicator of Celtic origin) in $10 \%$ of all cases, with no difference between winners and losers. (A $\chi^{2}$ test on the cross-tabulation of surname first letter and lottery status cannot reject that the variable is distributed the same for winners and losers.)

Finally, we constructed average characteristics from other males resident in the South in 1850 with the same surname, excluding members of our sample. ${ }^{20}$ Mean real estate wealth

\footnotetext{
${ }^{20}$ Although an earlier version of our work used only data from the half of Georgia (counties beginning with the letters "A" through "M") transcribed entirely in the $100 \%$ file, for this version we took advantage of the full transcription of all fields for the entire South to which we now have access.
} 
of those people with the same surname as the sample individuals is $\$ 1,200$, while the median wealth is below $\$ 300$. The surname average rate for illiteracy is $22 \%$. None of these measures differs between the winners and losers. ${ }^{21}$

Summary statistics for fertility and school attendance among the children of winners and losers are shown in Panel C. Outcomes measured here and in the rest of Table 1 are no longer expected to be the same between winners and losers and thus, unlike Panel B, are not useful as a balancing test. Lottery winners had, on average, 0.2 more children born after 1832 who survived to 1850 than did lottery losers. By contrast, the fraction of schooleligible children who attended school at any time during the 12 months prior to the census reference date (June 1, 1850) did not differ between the winners and losers. ${ }^{22}$

Additional characteristics for spouses and 1850 locations are compared in Panel D. Roughly equal percentages of spouses were illiterate among the winners and losers. Though winners and losers in our sample could, in principle, have been found anywhere in the U.S., most of the sample still resided in Georgia in 1850 (Figure 1 and Appendix Figure 3), while most of the balance outside Georgia was in Alabama. Although the fractions residing in Georgia and Alabama do not differ between the winners and losers, the equality of the distributions of winners and losers across counties is strongly rejected by a simple $\chi^{2}$ test. Lottery winners were slightly more likely than losers to reside in 1850 in Old Cherokee County (the counties settled through the 1832 Cherokee Land Lottery).

Panel E summarizes our measures of 1850 wealth, eighteen years after the lottery. We report real estate wealth, slave wealth, and the sum of these. Although we label the latter "total wealth," there are other forms in which wealth could be held that were not recorded in the 1850 census (a personal wealth question was added in 1860 and 1870). Mean wealth in all 3 measures (real estate, slave, and "total") are all several hundred dollars higher for lottery winners than for lottery losers. The economically large magnitude is similar to the value of winning a parcel that we calculated previously. Although winnings could in theory have been invested in a variety of instruments other than children, land, and slaves, such alternative investment opportunities (e.g. bank deposits, mortgages, stocks and bonds) were rare in the Deep South in the antebellum period. ${ }^{23}$ The baseline estimates suggest that the effect of winning a parcel in the lottery persisted for at least the two decades following the drawing.

The effect of winning a parcel can be seen well down into the 1850 wealth distribution. Bleakley and Ferrie (2013) show a positive effect on total wealth from winning the lottery at the median and above in the 1850 total wealth distribution. Even among households with

\footnotetext{
${ }^{21}$ Although this might be thought a weak test due to noise in the surname averages, note that surname averages (in results not shown) are statistically significant predictors of individual-level behavior even controlling for a variety of other covariates.

${ }^{2} 2$ We observe only children still present by 1850 in the lottery participant's household, so this small positive fertility result might reflect the more rapid departure of children from the households of losers than from the households of winners and no difference in fertility. When we examine fertility separately for children age 10 and under in 1850 (who would have been still present in their parents' home in 1850 regardless of the parents' lottery status) below, the effect persists, leading us to conclude that it is not driven by differential rates of departure from the homes of winners and losers.

${ }^{23}$ Ransom and Sutch (1988, Table A.1, pp. 150-1) report that the total value of slaves in the U.S. in 1860 (the first time the census reported both real and personal wealth) was $\$ 3.1$ billion. In that year, total real estate and personal estate in the South were $\$ 3.4$ billion and $\$ 4.7$ billion, respectively (IPUMS $18601 \%$ Sample: Ruggles et al., 2010). Thus, slaves accounted for $2 / 3$ of all personal wealth in 1860 , and land plus slaves accounted for $80 \%$ of total wealth in 1860 .
} 
less than $\$ 300$ in 1850 total wealth, fertility by 1850 was greater post-lottery. Further, wealth in 1840, just 8 years after the lottery, was higher — winners had one slave more on average and were fifty percent more likely to own at least one slave than losers in 1840 . There was thus clearly a strong direct effect of winning across the wealth distribution. The question that we now consider is whether that effect led to better outcomes for winners' children.

\section{Estimation strategy}

Our data allow us to analyze outcomes for lottery winners themselves, their children, and their grandchildren - a span of roughly 50 years from the date of the lottery. The treatment effect of winning a parcel in the lottery can be assessed directly by comparing mean outcomes for winners and losers (and their descendants), or by estimating a simple bivariate regression with a relevant outcome on the left- hand side and a dummy variable for winning a parcel on the right-hand side. We adopt the regression- based approach to permit both the inclusion of additional control variables and the continuous $1 / n$ lottery status indicator. ${ }^{24}$

We estimate OLS regressions of the following form:

$$
Y_{i j}=\gamma T_{j}+\beta X_{i j}+\delta_{a i}+\varepsilon_{i j}
$$

in which where $i$ is the individual, $j$ indexes the lottery-eligible person, $T_{j}$, denotes treatment - winning a parcel in the lottery - which is either a binary variable or a binary variable deflated by $1 / n$ to a continuous variable to account for multiple matches, and control variables are: $\delta_{a l}$ (a set of age dummies) and $X_{i j k}$ (a vector of other control variables specified below). The error term is allowed to vary by both $i$ and $j$. When we examine outcomes for the original lottery participants, $i=j$. But many of the regressions below use instead samples of children or grandchildren of the lottery participants, generating potentially numerous observations $(i)$ for each lottery participant $(j)$. In these regressions, standard errors will be clustered at the lottery participant $(j)$ level. The estimate of $\gamma$ that we recover should be uncontaminated by omitted-variable or endogeneity problems, as a result of the random assignment of treatment by the lottery.

We also employ an additional specification that incorporates characteristics measured at the level of surnames, in the simplest case adding a fixed effect for each surname. Such a specification controls for numerous differences that might be constant in family lines (patrilineal lines here, as we only have information on surnames), allowing the impact of winning a parcel in the lottery to persist within extended patrilineal families. Clark and Cummins (2013) and Güell et al. (2012) both highlight striking persistence in a variety of outcomes across family lines, an effect that surname fixed effects would absorb. Though the least common surnames no doubt contain more information regarding membership in a patrilineal family line, limiting attention to only the least common names would

\footnotetext{
${ }^{24}$ Although the random assignment of parcels among participants reduces the omitted-variable problem and thereby diminishes the need to introduce additional controls, such controls can improve the precision of our estimated treatment effect and reduce the residual variation. These controls can also reduce any biases resulting from our process for imputing lottery status, although the inability of lottery status to predict pre-determined outcomes reduces this concern.
} 
substantially limit our sample size, so we use all family names instead. At the same time, our imputation process for determining lottery status relies on matching by surname, so some differences introduced by this process can be absorbed by surname fixed effects.

To motivate our interpretation of $\gamma$, in Figure 2 we present a simple model of investments in children. The standard model of education features downward-sloping marginal benefits (MB) and upward-sloping marginal costs (MC) of time in school. (This model and additional cases are explored in detail in online Appendix E.) The intersection of MB and MC defines ${ }^{25}$ the optimal choice of schooling $\left(\mathrm{e}^{*}\right)$. But benefits occur in the future and costs are typically immediate. Thus low-wealth households might be constrained in their ability to finance up to $\mathrm{e}^{*}$. For simplicity, we represent this constraint in Figure 2 as a simple upper bound on time in school. In Case 1, lottery wealth relaxes the borrowing constraint from A to $\mathrm{B}$, and enables additional education as long as $\mathrm{MB}>\mathrm{MC}$. Thus, our preferred interpretation for $\gamma$ is as a test of parents' response to relaxing a (supposed) borrowing constraint. However, if families used the lottery windfall to buy more land, this could change the optimal amount of schooling for their children. We analyze this in Figure 2, Case 2. The opportunity cost of a child's time rises if their labor is more productive on the family farm (in a way that is imperfectly substitutable for hired labor). This is seen, for example, with the new curve $\mathrm{MC}^{\prime}$. But a larger farm is also a more complex enterprise, and the returns to having an educated child might actually rise, such as to $\mathrm{MB}^{\prime}$. Nevertheless, such changes in optimal schooling only matter if the schooling choice were unconstrained. The largely null results for child outcomes below might therefore be explained by a relaxation of the borrowing constraint and an exactly counteracting shift in the opportunity cost of child time (to $\mathrm{MC}^{\prime \prime}$ intersecting with $\mathrm{MB}^{\prime}$, e.g.). Such a coincidence would have to be repeated, as we shall see, by gender, for both young versus old children, for parents with different human capital, and for fathers of different ages, for all of whom the changes in the value of child labor are likely to be different. Such a coincidence would also not explain the lack of results for the wealth held by future generations, because the lottery windfall increases their lifetime productivity. ${ }^{26}$

\section{Effects on Child Quantity versus Child Quality}

Lottery winners tended to have (slightly) more children, but were no more likely than losers to send them to school. These results are found in Table 2, where we estimate equation (1). Panel A reports results when the dependent variable is the number of children born after 1832 (the year of the lottery) who were still present in the household in 1850. (Recall that the number of children born in the three years prior to the 1832 Lottery was not significantly

\footnotetext{
25 The assumption of an interior solution seems justified for the majority of children. In our sample, the average school-enrollment rate for children aged 5-17 is more than a third, and this rate peaks above half among children 11 years of age. The often noncontinuous path through school in that era means that this "above half" number is a lower bound on the fraction of children attending at least some school. Bleakley and Hong (2013) report that white children in the Antebellum South achieved literacy rates of approximately $85 \%$. Note further that the model in Figure 2 does not exhibit a poverty trap, in contrast to those found in models by Galor and Zeira (1993) and Moav (2005). Issues related to poverty traps are discussed in detail in online Appendix E. There we argue that the lottery winnings should be enough money to boost at least some children out of a human-capital poverty trap. We also fail to find evidence of Moav's claimed mechanism that families with low human capital will respond more along the fertility than education dimension.

${ }^{26}$ While it might be tempting to discuss the results below in terms of Becker's quantity/quality trade-off, the lottery's wealth shock shifts the budget constraint out. Therefore, it does not directly or indirectly identify a trade-off that occurs along an existing budget constraint.
} 
related to lottery status.) In the basic specification, we estimate lottery winners have 0.13 more children on average and, in the specification augmented with surname fixed effects, we estimate instead a coefficient of 0.18 . These numbers are consistent with the unconditional difference seen in Table 1 of 0.2 . The Poisson regression coefficients in the last column indicate a roughly $3 \%$ higher number of children born post- 1832 for winners than for losers.

Panel B of Table 2 examines school attendance by children in the household aged at least five years old but not more than 17 years old. (Note that this age range excludes children born prior to the lottery.) These children are linked to the lottery status of their father, and the standard errors are adjusted for clustering at the level of the father. ${ }^{27}$ The first column uses the OLS estimator and therefore this regression is a linear probability model, while the last column uses the logit estimator, with marginal effects evaluated at the mean of the observables and assuming the surname fixed effects are all zero. The resulting coefficients imply an effect of winning the lottery of close to zero, and we can rule out effects of more than a few percentage points. Columns (3)-(5) add additional controls for the household's 1850 location, though these are clearly choice variables from the household's perspective. ${ }^{28}$ As is evident, locational choice plays little role in understanding these results.

In Table 3, we consider some decompositions and possible mechanisms for the quantity/ quality result. One hypothesis for these results is that richer husbands might be able to remarry more easily (and/or to a younger spouse) if his first wife had died in childbirth (which was not an uncommon occurrence in this period). This higher remarriage probability could result in higher fertility in families headed by lottery winners. But we see in Columns 1 and 2 that there is not a statistically significant difference by lottery status in the wife being present or in the wife's age, if she is present. Next we consider the extensive margin of post-lottery fertility in Column 3, where we see that lottery winners are more likely to have children after 1832 than the lottery losers. Indeed, the entire CDF of the number of postlottery children $\left(N_{k p}\right)$ is shifted out for lottery winners, although such differences are strongest when assessing whether winners were more likely than losers to have had one or two additional postlottery children. Columns 5 and 6 show that the effect of winning the lottery on fertility persists over the 18 post-lottery years - both the number of children 0 10 and 11-17 are larger for winners. In Column 7, we find essentially no effect on the gender composition of children, suggesting that the fertility effect is not due to the differential survival of one gender or the other. Finally, in Columns 8-11, we obtain similar school-attendance results when decomposing the sample by gender or by broad age groups. Additional results in online Appendix Table E-1 reveal no difference by father's literacy in the impact of lottery winning on children's school attendance. We caution against placing undue weight on the fertility results because of the small magnitude and non-robustness of

\footnotetext{
${ }^{27}$ To account for the possibility that the fertility and school attendance results are a product of the age of lottery participants (on average 51 in 1850), online Appendix Table 8 replicates this analysis but with fathers disaggregated into two groups: age 50 and under in 1850 and over age 50 in 1850 . There is no effect of winning on children's school attendance in either group. The effect on postlottery fertility for winners is a bit stronger for the younger group, but this is no doubt an age effect - they are young enough that their family size was more likely to be increasing after 1832 than those over age 50 in 1850

${ }^{28}$ We further investigate this mechanism by examining characteristics of the 1850 county of residence in online Appendix G. Lottery winners are slightly more likely to end up in Old Cherokee County in 1850, although this difference in probabilities is quite small $(2.2 \%)$. Various other county-level outcomes are too similar across winners and losers to plausibly account for the individual-level results.
} 
the coefficients. Coefficients much less than unity indicates that perhaps the vast majority of the sample saw its fertility behavior unchanged by the wealth shock.

We have replicated much of the analysis in this section using a "placebo" sample, described in online Appendix B. We combined the list of 1832 Georgia land lottery winners with a sample of "eligibles" we generated by assuming that the lottery's rules required that participants had resided in South Carolina rather than Georgia in the three years before 1832. In this exercise, then, we identified "eligibles" as males with at least on child born in South Carolina in this interval and none born outside South Carolina in this intervalt. This was done to address the possibility that our method of identifying eligibles (based as it is on co-residence in 1850 with a child born during a particular three year period) has biased the sample in a way that spuriously generates outcome differences between winners and losers. None of the effects we see among winners in the "true" sample (higher wealth, a higher likelihood of residence in Old Cherokee County, and more children born post-1832) are present in the "placebo" sample.

In the same way, analysis of a sample of males directly linked from 1830 to 1850 without regard for their children's ages or birthplaces in online Appendix C allows us to say that our original sample is not biased toward differential outcomes for lottery winners and losers by our procedure for identifying eligibles. Online Appendix Table 2 replicates the fertility and school attendance analyses using the sample of households we linked directly from 1830 to 1850. There we find no fertility or school attendance effects. When that sample is divided into households that contained a child born in the five years prior to the lottery (though the lottery requirement was that families have resided in Georgia for the three years prior to the lottery, the census for 1830 uses five-year age bins) and those that did not, fertility and school attendance effects are absent in both. When it is divided into households that met our eligibility criteria (children born in Georgia and only in Georgia in the prelottery three-year window, and present in the household in 1850), fertility and schooling effects were again absent for both those meeting the criteria and those not meeting it. We conclude that the results above are not an artifact of how we constructed the main sample.

\section{Outcomes of the next generations in $\mathbf{1 8 7 0}$ and $\mathbf{1 8 8 0}$}

We now follow up on the outcomes in 1870 and in 1880 of children observed in the 1850 households. Many of those in the second generation following the lottery had formed households by 1880 , which also allows us to observe the childhood outcomes of the grandchildren of those who were eligible to participate in the 1832 Lottery. Note that here we are examining outcomes that are almost 50 years after the lottery took place.

The conditions under which lottery winning predicts linkage are discussed below. It should be noted that we only attempt to link male children across censuses, because female children would almost certainly change their surname at marriage. Linkage rates to 1870 and 1880 are less than $100 \%$ (37\% and 56\%, respectively), but are actually higher than for other studies using data linked across nineteenth century sources (e.g. Long and Ferrie 2013). The lower linkage rate for 1870 results from both the absence of parents' birthplaces (included for the first time in 1880) and the requirement we imposed that they be old enough to be 
household heads in 1870 in order for us to observe their wealth. Approximately $59 \%$ of the lottery-eligible men have at least one child in the 1880 sample. $^{29}$

The relationship between having a father win the 1832 Lottery and various outcomes for these children as adults and for their own children is presented in Table 4. As above, we present results from a basic specification that includes dummies for age (Panel A), and an augmented specification that controls for surname fixed effects (Panel B). For our purposes, the bulk of the outcomes of interest are drawn from the 1880 census, so we focus on those first. Note in Columns 1 and 2 that having a lottery-winning father is a significant predictor for the child being linked to the 1870 or 1880 census. This differential linkage seems to result from differences in the characteristics of given (first) names as recorded in 1850. Accordingly, if we condition on a variety of characteristics of the given name, lottery winning no longer significantly predicts differential linkage. Therefore, to our standard set of specifications, we add a Panel $\mathrm{C}$ in which we also control for the number of letters in the given name.

The impact of winning on the adult literacy of the winner's children is shown in Column 3, measured as whether the lottery participant's son is unable to read and unable to write. In Column 4, the outcome variable is the occupational score, in adulthood (1880), of the children of the lottery participants. Neither of these outcomes is significantly different when comparing the children of lottery winners to those of lottery losers. ${ }^{30}$ In Columns 5 through 7 , we consider wealth outcomes in 1870 , the last nineteenth-century census reporting wealth. ${ }^{31}$ We transcribed both real-estate and personal wealth, and the results here are for the sum of these two variables. ${ }^{32}$ To compare with the estimates above, we deflate 1870 wealth to 1850 dollars using the consumer price index from measuringworth.com (Williamson, 2013).

The 1870 total wealth is statistically and economically similar between control and treatment groups. An alternative point of comparison is a mechanical split of the lottery winnings among the average number of children. This would suggest a treatment effect in 1870 of $\$ 140$ (in 1850 dollars), which we also cannot robustly reject at conventional levels of confidence. On the other hand, we can reject values larger than that. Note that the deflator adjusts for inflation only and does not convert the 1870 wealth into its present-value equivalent; results for 1870 wealth would drop by a factor of 2 to 5 for annual interest rates

\footnotetext{
${ }^{29}$ We find similar results if we use other characteristics of the given name. Online Appendix Table 6 compares the pre-1832 characteristics of lottery winners and losers as in Table 1, but disaggregated by whether a father's son was linked to 1880 . The only characteristic that differs from the Table 1 results is the age of the lottery participant: among fathers linked to a son in 1880, winners were 0.6 years younger than losers. Consequently, we include father's age in the regressions in the section with sons as adults.

${ }^{30}$ Of the 24 results for 1880 in Table 4 , only 4 are statistically significant at the $10 \%$ level, only slightly more than the 2.4 we would anticipate finding by chance.

${ }^{31}$ The reliability of the 1870 wealth data has been challenged by, among others, Ransom and Sutch (1977). Poor quality 1870 data would attenuate any relationship between the father's 1850 wealth and the son's 1870 wealth. But this will be true for both the control and treated groups in our analysis. This relationship would also be attenuated by the abolition of slave wealth with the end of the Civil War, but here, too, unless this attenuation is different for winners and losers, we would not expect it to bias a difference in outcomes for the children of winners versus the children of losers. Online Appendix F reports a comparison between 1870 census wealth and 1870 property tax wealth and shows that, despite the supposed shortcomings of the 1870 census data, its striking correspondence to wealth reported by tax assessors was evident. Online Appendix Table 9 reports evidence of robust intergenerational wealth elasticities using these data. This suggests that the attenuation from measurement error is limited.

${ }^{32}$ Census enumerators were instructed to leave the wealth response blank for values below $\$ 100$. Above $\$ 100$, the logarithmic distribution of wealth appears close to normal; we fit a truncated normal to these values and use it to compute the expected value of wealth below the censoring point. We use this imputation for the blank values when constructing the log of total wealth. Results are similar if we drop the blank values or use an imputed value of one dollar. See Bleakley and Ferrie (2013) for more on this imputation.
} 
of $3 \%$ to $8 \%$. At standard confidence levels, we could handily reject a lotterywinning effect of $\$ 140$ in 1850 dollars for interest rates much above 3\% per annum. These estimates for the wealth of the sons are inconsistent with a claim of supernormal returns in intergenerational transmission. The sons of winners were no more likely to have positive wealth in 1870 , or to have more wealth in logs than the sons of losers in our preferred specification (Panel C). An expanded version of this table, including results for 1860 wealth, appears as online Appendix Table 7, Columns 8-10. ${ }^{33}$ There were no differences between the sons of winners and those of losers in 1860 wealth. As 1860 is prior to the Civil War and slave emancipation, this result cannot be the result of a combination of disproportionate investment in slaves by lottery winners and their subsequent loss of their slave wealth when slaves were freed. Finally, we show in online Appendix Figure 2 using a quantile regression of 1870 wealth on treatment that effects are similar across the distribution of 1870 wealth.

In Columns 8 through 11, we turn to outcomes in the third generation (the grandchildren of lottery participants) in 1880 . There are two principal outcomes we consider: illiteracy (Column 8) and school enrollment (Column 9). Differences in illiteracy between the grandchildren by lottery status of their paternal grandfather are not statistically significant and are small in magnitude. In contrast, the grandchildren of lottery winners have a 1 to 3 percentage point lower probability of attending school. (These two columns use restricted ages corresponding to the age ranges over which the variables are measured and/or meaningful.) The result for schooling is the opposite of what one would expect if wealth were relaxing a constraint on human-capital investment. Nor are these results consistent with moving along or relaxing a quantity/quality tradeoff in that there is lower fertility as well. Men whose fathers had won the lottery had fewer children by 1880 (Column 10), although this effect is never statistically significant. Nevertheless, the magnitude of this effect is approximately the same as it was for the previous generation. A regression at the grandfather level of winning on the number of grandchildren cannot reject equality between winners and losers in the 1832 lottery. Furthermore, the fact that the fertility effects in the first and second generations roughly cancel out indicates that the wealth shock induced only a onegeneration blip in the size of the dynasty.

\section{Discussion}

In this section, we address two distinct questions: (1) is there evidence in these data of a return to skill and were lottery winners aware of these returns? (yes); and (2) is there evidence of intergenerational correlations in outcomes at this time? (yes).

\subsection{Was there a return to skill in nineteenth-century Georgia and were winners aware of it?}

A possible response to the results above is that antebellum Georgia is not the right environment in which to observe parents investing in skills or facing a quantity/quality trade-

\footnotetext{
${ }^{33}$ This table also provides specifications with controls for birth order and family size, as well as a separate analysis for eldest sons only. We might expect that later-born children have outcomes that differ more between winners and losers, as the winnings were available to their families at a time when investments in children (e.g. schooling) might be expected to produce a higher return. Conversely, we might expect eldest sons to show a less pronounced impact of winning on human capital, but a greater impact on wealth if it was not divided equally among the household's children. In no case does any of these additional specifications generate results other than that seen in the baseline case: winning the lottery generate no positive outcomes in the next generation.
} 
off, perhaps because it was too early in that region's path of economic development. But was this indeed the case? The contemporary reader might be unduly influenced by the seemingly moribund state of education in the South after the Civil War. Nevertheless, Bleakley and Hong (2013) show that antebellum rates of school enrollment among white children in the South were considerably higher than postbellum rates, and, indeed, that the South would have caught up to the North by circa 1890 if the antebellum trends in school enrollment had continued after the Civil War.

Schultz (1975) has emphasized the importance of returns to education in agriculture once farming has passed out its "traditional" phase (in which prices are stable, long-used production techniques can be employed year after year, and there are no new technological or financial innovations that need to be dealt with). In light of the non-traditional nature of farming in Georgia from the 1830s forward (with new crops like new cotton varieties being introduced, and increasingly national and international markets for the state's products and wide year-to-year swings in prices), it would not be surprising to find a substantial value for education in this environment.

Lacking an intervention or instrument that specifically manipulates time in school, we cannot provide causal evidence on the return to schooling. Bleakley and Ferrie (2014) apply standard methods using observational data to get a first-pass estimate of these effects and find substantial (correlational) evidence of returns to skill in the same sample we have used here.

The manner in which lottery winners chose to use their windfall no doubt depended on the range of choices they perceived as available to them. If investing in the education of their children was not even part of their choice set (e.g. they were not aware of such opportunities at any cost, let alone at a cost that would be feasible to incur using their winnings), winners may have opted for either other investments (slaves, or more land), or immediate consumption. They may have done the same if investing in their children's education was mistakenly viewed as a low-return investment. ${ }^{34}$

It is difficult to know what lottery winners in mid-nineteenth century Georgia perceived to be the range of options open to them - there were no surveys and very little documentary evidence survives describing what the average farmer was thinking at the time. But what little evidence we possess suggests that the education of their children was indeed a recognized investment opportunity among poor farmers. Moreover, investment in the education of their children was seen as a high priority as budget constraints were relaxed.

Consider the case of Wiley Webb, a participant in the portion of the 1832 Georgia land lottery in which forty acre lots in a belt of southern Old Cherokee County thought to contain gold deposits were distributed (Williams 1989, pp. 530-532). Webb was a 34 year old farmer in Walton County, Georgia in 1832, living with his parents, described as illiterate and a "very poor man" (Williams 1989, p. 532). A contemporary reported that "He was making spinning wheels and chairs with his foot lathe, and cotton baskets to support a large family."

\footnotetext{
34 Jensen (2010) and Bursztyn (2013) provide examples from modern developing economies in which people are either unaware of returns to education or simply prefer that resources be spent in other ways.
} 
(Coulter 1962, p. 199). He won lot \#727 which was thought to contain a particularly rich gold deposit and immediately attracted the interest of several mining companies. $\mathrm{He}$ auctioned the parcel within days of winning it in the lottery and received $\$ 10,000$ ( $\$ 4,000$ as down payment and a promise of the remaining $\$ 6,000$ ). Upon learning how much his lot had fetched, Webb immediately proclaimed that he would use the funds to provide an education for his children. A contemporary reported just five or six years later that Webb, who had by then moved to Gwinnett County, Georgia, adjacent to his home county, "had bought a very good little farm and two negroes, and was educating his children and doing well" (Coulter 1962, p. 200).

Another piece of evidence on the value placed on schooling even among the poor farmers of Georgia at this time is a report that the structure of the school system (in which subsidies for tuition were provided only to families deemed "poor" by their county) discouraged some farmers from sending their children to school: "Unquestionably, many a Georgian, poor but proud, let his children grow up in illiteracy, rather than set them apart in the school as 'poor children"” (Coulter 1921, p. 29). These farmers were clearly aware of the availability of schooling and were prepared to send their children to school but for the stigma associated with the nomenclature employed by the state's funding system.

Finally, one of the few farmers from this time and place whose records (a diary and account book) have survived was clearly concerned with the education of his children. "The education of his twelve children was a continuing responsibility for [Edward] Oxford for twenty years or more," though he was himself illiterate until a late age (Biehle 1968, pp. 194-5) His accounts report expenditures that averaged $\$ 2.50-\$ 4.00$ per quarter per student (Biehle 1968, p. 195).

Even seemingly contrary opinions admit of the possibility that at least some farmers were eager to educate their children if they possessed adequate resources. Sunday school was a popular expedient among some but not all rural Georgians in the absence of adequate public schools: "For some of the more ignorant, this method was the only method, since they believed that education was immoral and evil unless linked up intimately with religion. There were others 'so far sunk in ignorance and poverty together, as not to believe that the ability to read was worth the struggle that it would cost them to give it to their children"” (Coulter 1925, p. 26). This description, though, is applied only to "some of the more ignorant," and not the population generally.

Families that won parcels in the lottery clearly did not invest more in their children's human capital, but were they simply exploiting a quantity/quality trade-off by having more children? This is implausible in light of (1) the very small effect of winning on the number of children in winners' households (and the negative sign on the number of children in winners' sons' households), and (2) the associated high value for children this would imply. For example, winners had between 0.13 and 0.18 children more than losers (Table 2), despite their having won as much as $\$ 700$ in the lottery. This implies that an additional child was worth between $\$ 3,600$ and $\$ 5,300$. Kotlikoff (1979) reports that a prime-age male slave could be purchased at auction in 1832 in New Orleans for \$701. Given high antebellum infant and child mortality rates, parents would have had to place an implausibly high 
premium on their own children's labor (and any non-pecuniary benefits from populating their households with their own children rather than slaves) for the measured effect of lottery winning on fertility to be consistent with investment at the extensive margin (quantity) in lieu of investment at the intensive margin (quality). ${ }^{35}$

\subsection{Intergenerational correlations}

Next, we consider the etent to which outcomes are in fact correlated across generations in this context. As an example of correlation across generations, we examine the 1850 outcomes as predictors of the son's own 1870 wealth. There is evidence of a strong relationship between the log wealth of fathers and sons. In the lottery-eligible sample, the elasticity of son's 1870 wealth with respect to the father's 1850 wealth is between 0.13 and 0.28 (depending on the treatment of zeroes) and statistically significant (in all cases). ${ }^{36}$ This linkage persists despite the intervening Civil War that destroyed much of the South's physical capital (though most had been restored by 1870), but - perhaps more importantly resulted in emancipation and the disappearance from slaveowners' balance sheets of a significant quantity of capital. Despite the loss of this capital, the link between fathers' and sons' wealth remains strong. ${ }^{37}$ This is perhaps not surprising as the war would not have destroyed human capital acquired before it took place and post-war land reform was minimal. The other intergenerational correlations in the control sample (shown in online Appendix Table 10) are also substantively large and statistically significant at the one percent level between father's $1850 \log$ total wealth and his children's 1850 school attendance $(0.25), 1880$ literacy $(0.11)$ and 1880 occupational score $(0.11)$, and between the father's $1850 \log$ total wealth and his grandchildren's 1880 school attendance (0.04). An example of such an intergenerational correlation can be seen in online Appendix Figure 1: the relationship between parents' 1850 wealth and the probability that a child would attend school is positive and increasing in wealth across the 1850 total wealth distribution.

We simulate the relationship between parents' wealth and sons' outcomes in online Appendix D. The observed outcomes for lottery winners fall well short of the outcomes we would predict given the magnitude of the wealth shock they receive. The absence of an effect when wealth is randomly assigned and the presence of a strong cross-sectional relationship like that in online Appendix Figure 1 suggests that the latter is not causal. Rather, it suggests the positive relationship observed between parents' and children's outcomes results from the presence of an unobserved factor linked within families across generations and associated with better outcomes for some parents and for their children.

\footnotetext{
35 Another way to assess whether parents were exploiting a quantity/quality tradeoff is to compute how many children a family could afford at the price such a tradeoff implies. The approximate permanent income for an unskilled worker from forty years of unskilled wages at $\$ 18 /$ month would sum to $\$ 8640$, which would be below $\$ 4000$ if discounted at $5 \%$ per annum. If the child price were indeed $\$ 3,600$, only very small families would be possible within the budget constraint. In contrast, unskilled workers routinely had families with more than six children.

36 These results, as well as intergenerational wealth elasticities for 1860 (which range from 0.18 to 0.45 and are statistically significant), appear in online Appendix Table 9. Most of the 1860 and 1870 estimates lie below the modern estimated intergenerational wealth elasticity of 0.37 reported by Charles and Hurst (2001 Charles and Hurst (2003) for the entire U.S.

${ }^{37}$ In an additional analysis (no shown), we interact (1) the fraction of the father's 1850 wealth that was comprised of slaves with (2) the father's lottery status. If the abolition of slavery and the consequent loss of slave wealth was driving the failure of slave-holding fathers to transmit lottery winnings to their sons, this interaction should be negative. In no specification can we reject the null hypothesis that the coefficient on the interaction term is zero. See footnote 31 for further discussion of the quality of the 1870 wealth data. See page 23 for further discussion of the impact of emancipation on wealth transmission from fathers in 1850 to sons in 1870.
} 


\section{Conclusions}

Georgia's 1832 land provides a unique opportunity to assess the impact of shocks to wealth, in that the random assignment implied that the wealth shock was uncorrelated with individual characteristics. We assess the impact on the winners themselves and their families into the third generation. Using 1850 Census microdata, we draw a sample of male household heads that likely were eligible for the lottery. The rate of registration for this eligible population was very high. We identify the lottery winners using Georgia state records and define them as our treatment group. We cannot reject that the treatment variable was randomly assigned in several balancing and placebo tests. We estimate that lottery winners won some $\$ 700$ - close to median wealth in 1850 and the equivalent of more than five years of wages for an unskilled laborer in the South.

We focus on child outcomes in response to this wealth shock. Lottery winners slightly increased their family size after the lottery more than non-winners, but were not more likely to send their children to school. Children of lottery winners did not have more wealth, literacy, or income as adults. Further, the grandchildren of winners were not more likely to be literate or attend school. Indeed, the sons of lottery winners actually have fewer children and, if anything, send their children to school less than the control-group sons. The reduction of treated fertility in the second generation actually leaves the estimated number of grandchildren similar between control and treatment groups, effectively nullifying any fertility effect from treatment in the long run.

Despite the substantial size of the completely random financial windfall received by lottery winners and the presence of returns to human capital seen in cross-sectional data at this time, it does not appear that lottery winners invested more in their children (or that winners' children in turn invested more in their own children) than did losers (or losers' children). These findings are inconsistent with parents' financial resources being a significant explanatory factor for the level or dispersion in intergenerational human-capital investments in this period. The results are also inconsistent with a wealth-based "poverty trap" for human capital. The observed intergenerational links are instead consistent with the presence of underlying characteristics that are (a) associated with better outcomes, and (b) passed down along family lines.

\section{Supplementary Material}

Refer to Web version on PubMed Central for supplementary material.

\section{Acknowledgments}

For comments on early versions, we thank Lou Cain, Greg Clark, Robert Pollack, Chris Roudiez, Rachel Soloveichik, and seminar and conference participants at the NBER Cohort Studies meeting, the Stanford SITE meeting, the University of Washington, the University of Michigan, the University of Chicago, and the Minnesota Population Center and for helpful comments, to Steven Ruggles for access to a preliminary version of the 1850 fullcount file. Bleakley gratefully acknowledges research support from the Center on Aging (which provided a pilot grant), the Center for Population Economics (funded under National Institutes of Health Grant P01 AG010120), the Stigler Center, and the Deans' Office of the Booth School of Business, all at the University of Chicago. 


\section{References}

Akresh, Richard, de Walque, Damien, Kazianga, Harounan. Cash Transfers and Child Schooling: Evidence from a Randomized Evaluation of the Role of Conditionality. 2013 Jan. World Bank Policy Research Working Paper 6340

Baird, Sarah, McIntosh, Craig, Ozler, Berk. Cash or Condition? Evidence from a Cash Transfer Experiment. Quarterly Journal of Economics. 2011; 126(4):1709-53.

Becker, Gary. A Treatise on the Family. Chicago: University of Chicago Press; 1982.

Becker, Gary S., Tomes, Nigel. Human Capital and the Rise and Fall of Families. Journal of Labor Economics. $1986 \mathrm{Jul}$; 4(3):S1-39.

Biehle, Reba Strickland. Edward Oxford: Pioneer Farmer of Middle Georgia. Georgia Historical Quarterly. 1968 Jun; 52(2):187-198.

Black, Sandra E., Devereux, Paul J., Salvanes, Kjell G. Why The Apple Doesn't Fall Far: Understanding Intergenerational Transmission Of Human Capital. American Economic Review. 2005 Mar; 95(1):437-449.

Bleakley, Hoyt, Ferrie, Joseph. Up from Poverty? The 1832 Cherokee Land Lottery and the Long-run Distribution of Wealth. 2013. NBER Working Paper No. w19175

Bleakley, Hoyt, Ferrie, Joseph. Returns to Human Capital in the Mid-Nineteenth Century US. 2014. Working Paper

Bleakley, Hoyt, Hong, Sok Chul. When the Race between Education and Technology Goes Backwards: The Postbellum Decline of White School Attendance in the Southern U.S. University of Chicago; 2013 Apr. Unpublished manuscript

Bursztyn, Leonardo. Poverty and the Political Economy of Public Education Spending: Evidence from Brazil. 2013. Working paper

Bursztyn, Leonardo, Coffman, Lucas C. The Schooling Decision: Family Preferences, Intergenerational Conflict, and Moral Hazard in the Brazilian Favelas. Journal of Political Economy. 2012; 120(3):359-397.

Charles, Kerwin Kofi, Hurst, Erik. The Correlation of Wealth across Generations. University of Chicago, Booth School of Business; 2001 Jun. Working Paper

Charles, Kerwin Kofi, Hurst, Erik. The Correlation of Wealth across Generations. Journal of Political Economy. 2003 Dec; 111(6):1155-1182.

Chevalier, Arnaud. Parental Education and Child's Education: A Natural Experiment. 2004. IZA Discussion Paper No 1153

Clark, Gregory. The Son Also Rises. Princeton: Princeton Univ. Press; 2014.

Clark, Gregory, Cummins, Neil. What is the True Rate of Social Mobility? Surnames and Social Mobility, England 1800-2012. 2013. Unpublished manuscript

Coulter, E Merton. The Ante-Bellum Academy Movement in Georgia. Georgia Historical Quarterly. 1921:11-42.

Coulter, E Merton. A Georgia Educational Movement During the Eighteen Hundred Fifties. Georgia Historical Quarterly. 1925:1-33.

Coulter, E Merton. Reminiscences of Benjamin Franklin Matthews. Georgia Historical Quarterly. 1962:195-206.

Dahl GB, Lochner L. The impact of family income on child achievement: Evidence from the earned income tax credit. American Economic Review. 2012; 102(5):1927-1956.

Galor, Oded, Zeira, Jospeh. Income Distribution and Macroeconomics. Review of Economic Studies. 1993 Jan.60:35-52.

Gregg, Matthew T., Wishart, David M. The price of Cherokee removal. Explorations in Economic History. 2012; 49(4):423-442.

Güell, Maia, Rodriguez, Jose V., Telmer, Christopher I. Intergenerational Mobility and the Informational Content of Surnames. 2012 Jan. Unpublished manuscript

Jensen, Robert. The (perceived) returns to education and the demand for schooling. Quarterly Journal of Economics. 2010; 125(2):515-548. 
Kotlikoff, Laurence J. The Structure of Slave Prices in New Orleans, 1804 to 1862. Economic Inquiry. 1979 Oct; 17(4):496-518.

Lindahl, Mikael, Palme, Mårten, Massih, Sofia Sandgren, Sjögren, Anna. Long-Term Intergenerational Persistence of Human Capital An Empirical Analysis of Four Generations. Journal of Human Resources. 2015; 50(1):1-33.

Long, Jason, Ferrie, Joseph. Intergenerational Occupational Mobility in Great Britain and the United States since 1850. American Economic Review. 2013 Jun; 103(4):1109-37.

Margo, Robert A., Villaflor, Georgia C. The Growth of Wages in Antebellum America: New Evidence. The Journal of Economic History. 1987 Dec; 47(4):873-895.

Mayer, Susan E. What money can't buy: Family income and children's life chances. Harvard University Press; 1997.

Moav, Omer. Cheap Children and the Persistence of Poverty. The Economic Journal. 2005 Jan.115:88110.

Olivetti, Claudia, Daniele, Paserman M. In the Name of the Son (and the Daughter): Intergenerational Mobility in the United States, 1850-1940. American Economic Review. 2015 Forthcoming.

Oreopoulos, Philip, Page, Marianne E., Stevens, Ann Huff. The Intergenerational Effects of Compulsory Schooling. Journal of Labor Economics. 2006 Oct; 24(4):729-760.

Ransom, Roger L., Sutch, Richard. One kind of freedom: The economic consequences of emancipation. Cambridge University Press; 1977.

Ransom, Roger, Sutch, Richard. Capitalists without Capital: The Burden of Slavery and the Impact of Emancipation. Agricultural History. 1988 Summer;62(3):133-160.Quantitative Studies in Agrarian History

Ruggles, Steven, Alexander, J Trent, Genadek, Katie, Goeken, Ronald, Schroeder, Matthew B., Sobek, Matthew. Integrated Public Use Microdata Series: Version 5.0 [Machine-readable database]. Minneapolis, MN: Minnesota Population Center; 2010. [producer and distributor]

Sacerdote, Bruce. Slavery and the Intergenerational Transmission of Human Capital. The Review of Economics and Statistics. 2005 May; 87(2):217-234.

Schultz TW. The Value of the Ability to Deal with Disequilibria. Journal of Economic Literature. 1975 Sep; 13(3):827-846.

Shadburn, Don L. Cherokee Planters in Georgia, 1832-1838: Historical Essays on Eleven Counties in the Cherokee Nation of Georgia. WH Wolfe Associates, Historical Publications Division; 1990.

Smith, James F. The Cherokee land lottery, containing a numerical list of the names of the fortunate drawers in said lottery, with an engraved map of each district. New York: Harper and Brothers; 1838 .

State of Georgia. Acts of the General Assembly of the State of Georgia Passed at an Annual Session in October, November, and December, 1830. Milledgeville: Camak and Ragland; 1831.

State of Georgia. Acts of the General Assembly of the State of Georgia Passed at an Annual Session in October, November, and December, 1831. Milledgeville: Prince and Ragland; 1832.

Williams, H David. Gambling Away the Inheritance: The Cherokee Nation and Georgia's Gold and Land Lotteries of 1832-33. The Georgia Historical Quarterly. 1989 Fall;73(3):519-539.Special Issue Commemorating the Sesquicentennial of Cherokee Removal 1838-1839

Weiman, David F. Peopling the land by lottery? The market in public lands and the regional differentiation of territory on the Georgia frontier. Journal of Economic History. 1991; 51(04):835860 .

Williamson, Samuel H. Seven Ways to Compute the Relative Value of a U.S. Dollar Amount, 1774 to present. 2013. MeasuringWorth.com, accessed March 15, 2013

Wishart, David M. Evidence of surplus production in the Cherokee nation prior to removal. Journal of economic history. 1995; 55(01):120-138. 


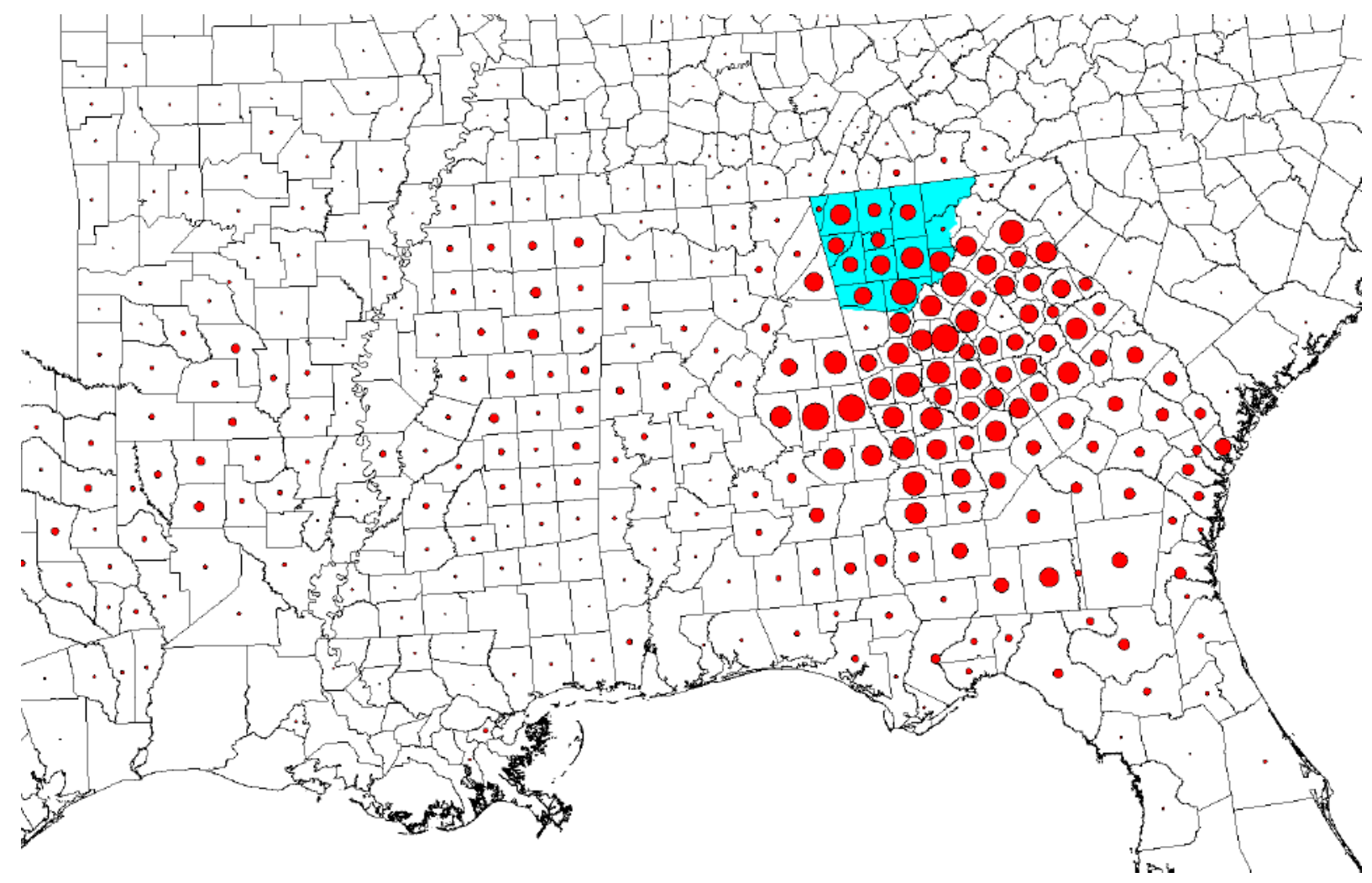

Figure 1. Old Cherokee County and the 1850 Locations of the Sample

Notes: This figure displays a map of the southeastern United States with information on the location (by county) in 1850 of the lottery-eligible households in our main sample. Black lines indicate the 1850 county boundaries, drawn from the NHGIS database. The area shaded in blue in northwest Georgia denotes old Cherokee County, which was allocated by the Cherokee Lottery of 1832. The sample consists of all household heads in the 1850 census with children born in Georgia during the three years prior to the Cherokee Land Lottery of 1832 and no children born outside of Georgia during the same period. If households in our sample are resident in a county in 1850, we place a red dot at the county centroid. The area of a dot is proportional to the number of sample households resident in that county. A minor fraction of sampled households resides in counties outside the frame of this map. Such households are included in the econometric analysis, but we chose to zoom in on this region to make the feature is legible in this figure; see Appendix Figure 3 for the full country. Data sources and additional variable and sample definitions are found in the text. 

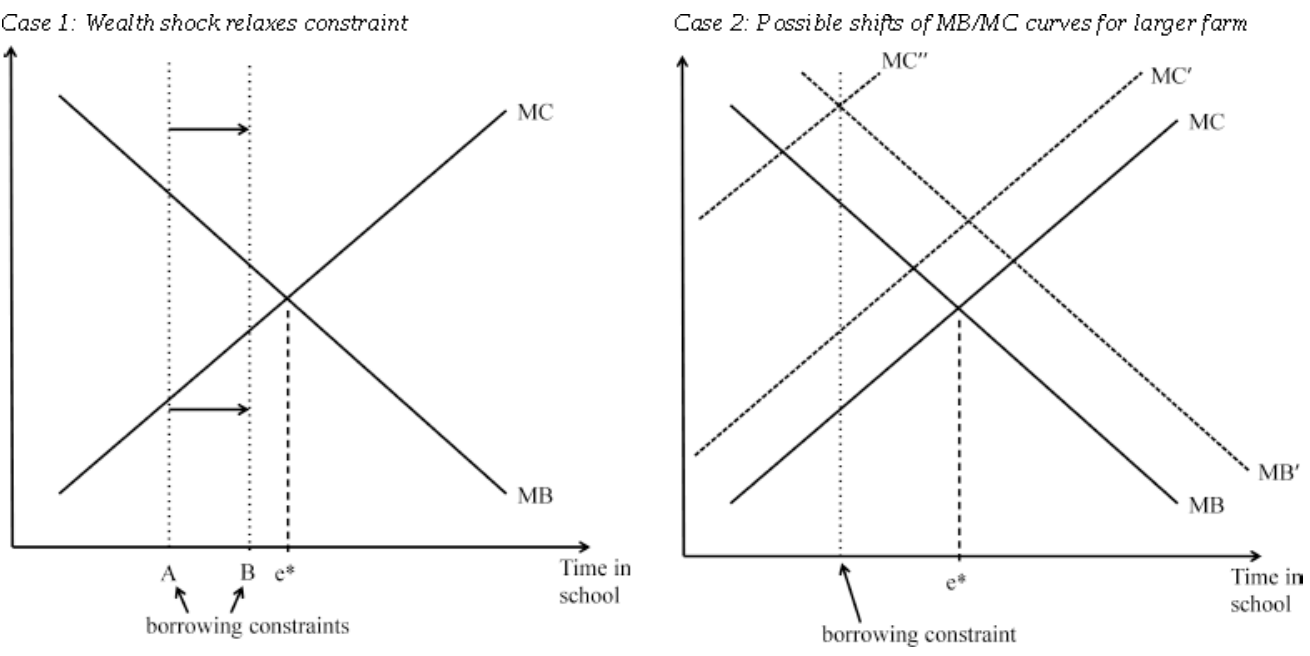

Figure 2. Standard Model of Education, Augmented with Credit Constraint

Notes: This figure displays the marginal benefit (MB) and marginal cost (MC) curves for the standard model of the optimal choice of schooling. Panels show various assumptions about how the lottery winnings affect the borrowing constraint and the MB and MC curves. 
Table 1

Summary Statistics

\begin{tabular}{|c|c|c|c|c|}
\hline & Whole Sample & Lottery "Losers" & Lottery "Winners" & $\begin{array}{c}(4) \\
\text { P-value, } \\
\text { mean } \\
\text { difference } \\
{[\mathrm{N}]} \\
\end{array}$ \\
\hline & \multicolumn{4}{|c|}{ Panel A: Lottery Winner or Loser } \\
\hline $\begin{array}{l}\text { Dummy for unique } \\
\text { match to Smith } \\
\text { (1838) list }\end{array}$ & $0.124(0.329)$ & 0 & 1 & - \\
\hline \multirow{2}{*}{$\begin{array}{l}\text { Dummy for match } \\
\text { to Smith }(1838) \text {, } \\
\text { deflated to } 1 / \mathrm{n} \text { in } \\
\text { case of ties }\end{array}$} & $0.155(0.335)$ & $0.037(0.121)$ & $0.995(0.053)$ & $0.000[14375]$ \\
\hline & \multicolumn{4}{|c|}{ Panel B: Predetermined Outcomes } \\
\hline Age, in years & $51.2(8.5)$ & $51.3(8.5)$ & $50.9(8.6)$ & $0.122[14375]$ \\
\hline Born in Georgia & $0.497(0.500)$ & $0.497(0.500)$ & $0.498(0.500)$ & 0.889 [14375] \\
\hline $\begin{array}{l}\text { Born in South } \\
\text { Carolina }\end{array}$ & $0.212(0.408)$ & $0.210(0.407)$ & $0.222(0.416)$ & $0.263[14375]$ \\
\hline $\begin{array}{l}\text { Born in North } \\
\text { Carolina }\end{array}$ & $0.180(0.384)$ & $0.180(0.384)$ & $0.178(0.383)$ & 0.804 [14375] \\
\hline $\begin{array}{l}\text { Number of } \\
\text { Georgia-born } \\
\text { children in the } \\
\text { three years prior to } \\
\text { the lottery }\end{array}$ & $1.333(0.542)$ & $1.333(0.541)$ & $1.332(0.542)$ & 0.910 [14375] \\
\hline $\begin{array}{l}\text { Cannot read and } \\
\text { write }\end{array}$ & $0.147(0.354)$ & $0.147(0.354)$ & $0.142(0.350)$ & $0.593[14340]$ \\
\hline $\begin{array}{l}\text { Number of letters } \\
\text { in surname }\end{array}$ & $6.19(1.61)$ & $6.20(1.62)$ & $6.13(1.51)$ & $0.072[14375]$ \\
\hline $\begin{array}{l}\text { Frequency with } \\
\text { which surname } \\
\text { appears in sample }\end{array}$ & $36.2(46.3)$ & $36.3(46.9)$ & $35.3(41.9)$ & 0.380 [14375] \\
\hline $\begin{array}{l}\text { Surname begins } \\
\text { with "M" or "O" }\end{array}$ & $0.101(0.302)$ & $0.101(0.301)$ & $0.104(0.305)$ & 0.740 [14375] \\
\hline $\begin{array}{l}\text { Mean wealth of } \\
\text { families in the } \\
\text { South with same } \\
\text { surname }\end{array}$ & $1203.4(445.4)$ & $1204.5(455.1)$ & $1195.7(370.5)$ & 0.373 [14093] \\
\hline $\begin{array}{l}\text { Median wealth of } \\
\text { families in the } \\
\text { South with same } \\
\text { surname }\end{array}$ & $184.1(162.3)$ & $184.6(167.3)$ & $181.0(121.8)$ & 0.276 [14093] \\
\hline $\begin{array}{l}\text { Mean illiteracy of } \\
\text { adults in the South } \\
\text { with same surname }\end{array}$ & $0.175(0.043)$ & $0.175(0.044)$ & $0.176(0.039)$ & 0.124 [14093] \\
\hline \multirow[t]{2}{*}{$\begin{array}{l}\text { Mean school } \\
\text { attendance of } \\
\text { children in the } \\
\text { South with same } \\
\text { surname }\end{array}$} & $0.323(0.052)$ & $0.323(0.052)$ & $0.323(0.049)$ & 0.998 [13975] \\
\hline & \multicolumn{4}{|c|}{ Panel C: Fertility and School Attendance } \\
\hline $\begin{array}{l}\text { Number of children } \\
\text { in household born } \\
\text { after the } 1832 \\
\text { lottery }\end{array}$ & 3.955 (2.546) & $3.930(2.539)$ & $4.135(2.586)$ & 0.002 [14375] \\
\hline
\end{tabular}




\begin{tabular}{|c|c|c|c|c|}
\hline & Whole Sample & Lottery "Losers" & Lottery “Winners" & $\begin{array}{c}(4) \\
\text { P-value, } \\
\text { mean } \\
\text { difference } \\
{[\mathrm{N}]} \\
\end{array}$ \\
\hline \multirow{2}{*}{$\begin{array}{l}\text { School attendance } \\
\text { among children } \\
\text { aged 5-17, } \\
\text { inclusive }\end{array}$} & $0.342(0.474)$ & $0.342(0.475)$ & $0.341(0.474)$ & 0.799 [47749] \\
\hline & \multicolumn{4}{|c|}{ Panel D: Other Outcomes } \\
\hline $\begin{array}{l}\text { Spouse cannot read } \\
\text { and write }\end{array}$ & $0.235(0.424)$ & $0.236(0.424)$ & $0.231(0.421)$ & $0.676[11563]$ \\
\hline Resides in Georgia & $0.723(0.447)$ & $0.722(0.448)$ & $0.729(0.445)$ & $0.548[14375]$ \\
\hline Resides in Alabama & $0.144(0.351)$ & $0.144(0.351)$ & $0.145(0.352)$ & 0.935 [14375] \\
\hline \multirow[t]{2}{*}{$\begin{array}{l}\text { Resides in Old } \\
\text { Cherokee County }\end{array}$} & $0.113(0.317)$ & $0.111(0.314)$ & $0.126(0.332)$ & $0.074[14375]$ \\
\hline & \multicolumn{4}{|c|}{ Panel E: Measures of Wealth in 1850 (18 years after the Lottery) } \\
\hline Real-estate wealth & $1999.0(4694.2)$ & $1970.8(4422.0)$ & $2198.2(6290.1)$ & $0.068[13094]$ \\
\hline Slave wealth & $1339.1(5761.0)$ & $1297.3(5329.7)$ & $1635.3(8189.0)$ & $0.021[14375]$ \\
\hline \multirow[t]{2}{*}{$\begin{array}{l}\text { Total wealth (sum } \\
\text { of wealth in real } \\
\text { estate and slaves) }\end{array}$} & $3323.7(8691.0)\{100,800,3000\}$ & $3245.5(7952.9)\{100,800,3000\}$ & $3876.5(12734.4)\{100,1000,3550\}$ & $0.006[13094]$ \\
\hline & \multicolumn{4}{|c|}{ Panel F: Select Variables for Those with Below $\$ 300$ in 1850 Total Wealth } \\
\hline $\begin{array}{l}\text { Number of children } \\
\text { in household born } \\
\text { after the } 1832 \\
\text { lottery }\end{array}$ & $3.905(2.471)$ & $3.878(2.453)$ & $4.098(2.591)$ & $0.063[4506]$ \\
\hline $\begin{array}{l}\text { Number of slaves } \\
\text { in } 1840\end{array}$ & $1.4(6.7)$ & $1.3(6.6)$ & $2.3(7.4)$ & $0.074[1761]$ \\
\hline $\begin{array}{l}\text { Has at least one } \\
\text { slave in } 1840\end{array}$ & $0.190(0.392)$ & $0.179(0.384)$ & $0.255(0.437)$ & $0.012[1761]$ \\
\hline
\end{tabular}

Notes: This table displays summary statistics for the main data used in the present study. The sample consists of all household heads in the 1850 census with children born in Georgia during the three years prior to the Cherokee Land Lottery of 1832 and no children born outside of Georgia during the same period. Column (1) presents means and standard deviations (in parentheses) of variables for this entire sample. We use two measures of whether the person won land in the drawing for the Cherokee Land Lottery of 1832 . The first measure is coded to 1 if that person is a unique match to a name found on the list of winners published by Smith (1838); anyone else in the sample is coded to zero. The second measure takes individuals that "tie" for a match to the Smith list with (n-1) other observations and recodes them to $1 / \mathrm{n}$. These variables are summarized in Panel A. Columns (2) and (3) present means and standard deviations of variables for the subsamples of, respectively, lottery losers and winners (decomposed using the first measure). Column (4) presents the P-value on the test of zero difference in means between the subsamples of losers and winners. In square brackets, we report the sample size used for this test, although the test involving children or surnames adjust for the clustering of errors. With the exception of the measure of surname length, we use the Soundex version of each name to account for minor spelling differences. For the variables that are means by surname, we use a preliminary copy of the $1850100 \%$ census file to construct average fertility, school attendance, and real-estate wealth among households in Alabama, Florida, Georgia Kentucky, Mississippi, North Carolina, South Carolina, Tennessee, and Virginia, for each (soundex) surname. (Those individuals that appear in our lottery-eligible sample are excluded from the construction of these indices.) Real-estate wealth is as reported on and transcribed from the manuscript pages of the 1850 Census of Population. Slave wealth was estimated by linking the household to the 1850 Slave Schedule and imputing a market value of slave holdings adjusting for the reported ages and gender of slaves on the Schedule. In curly brackets in Panel E, we report the 25th, 50th, and 75th percentiles of wealth. The number of slaves in 1840 was reported in the 1840 census population manuscripts to which these families were linked. Data sources and additional variable and sample definitions are found in the text. 







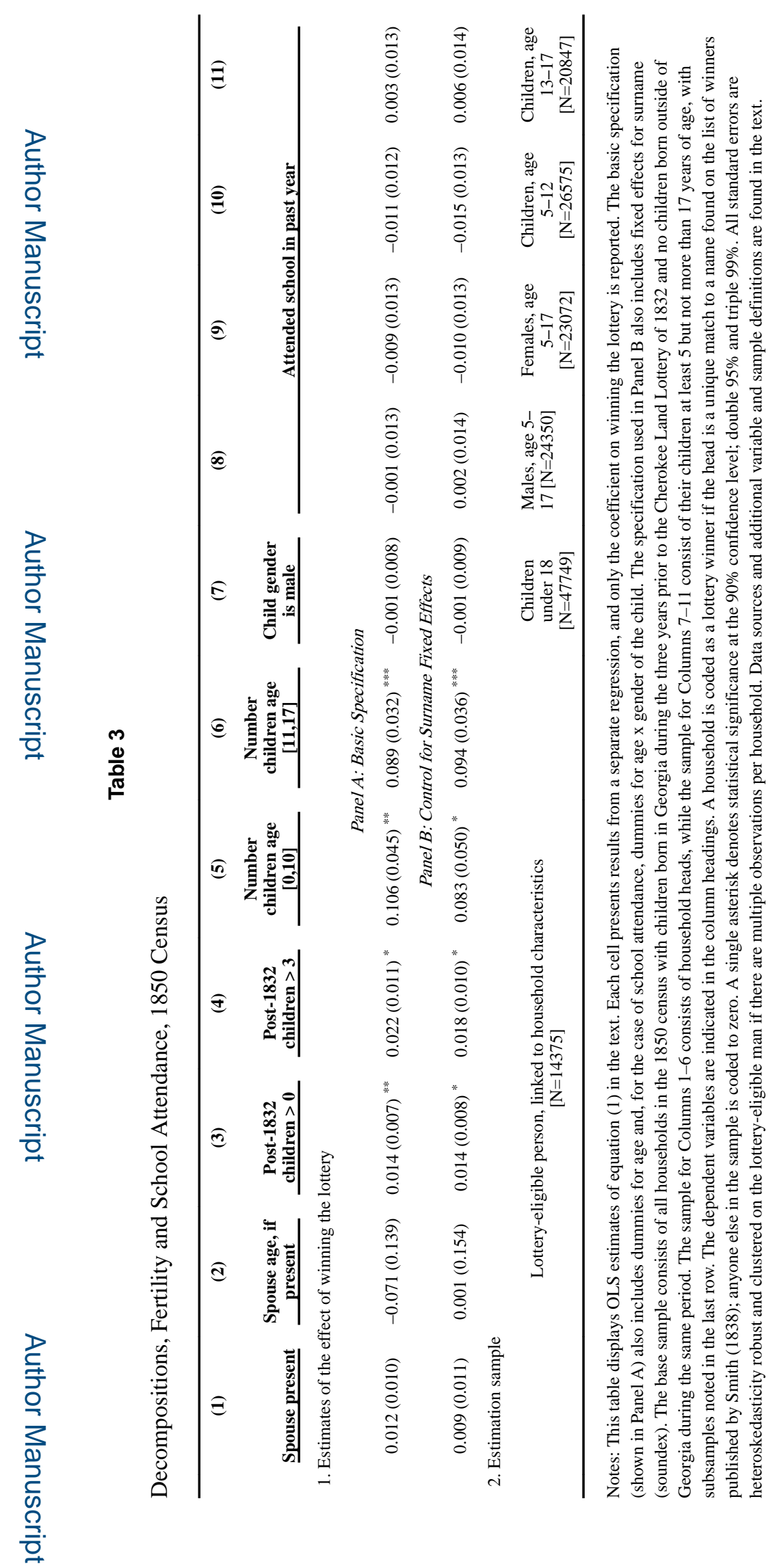

Q JEcon. Author manuscript; available in PMC 2017 August 01. 


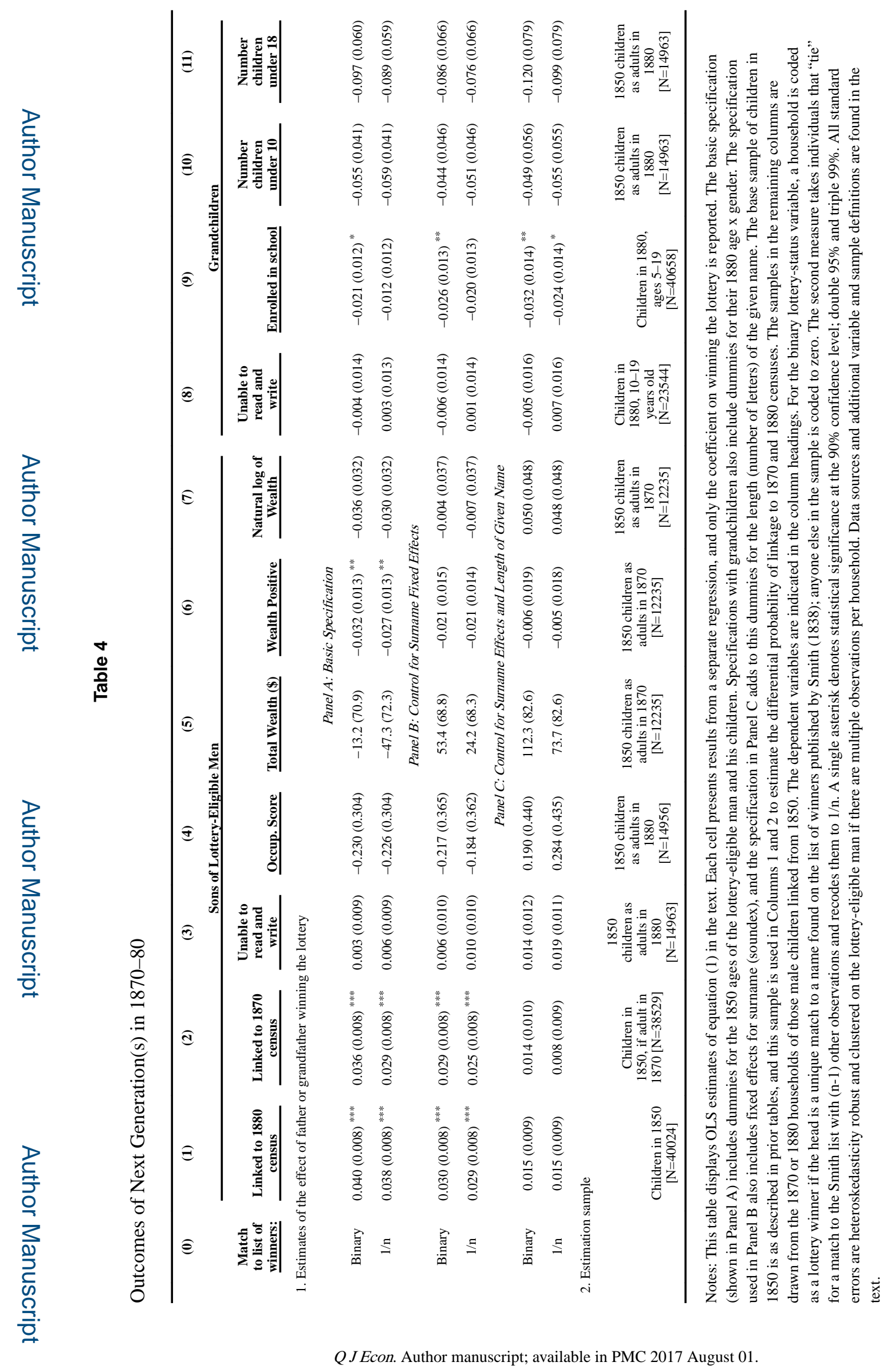

